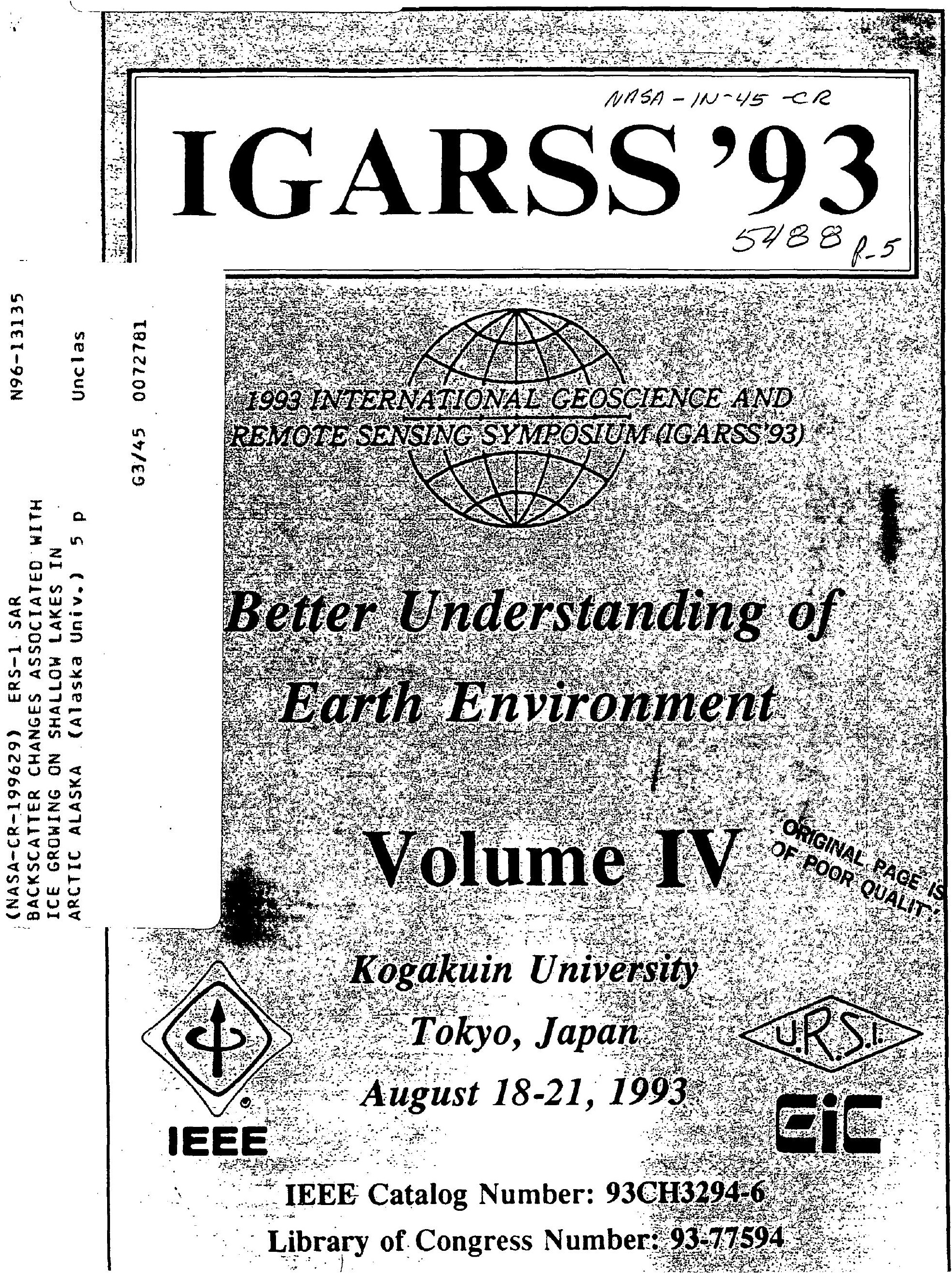




\title{
ERS-1 SAR BACKSCATTER CHANGES ASSOCIATED WITH ICE GROWING ON SHALLOW LAKES IN ARCTIC ALASKA
}

\author{
M. O. Jeffries ${ }^{1}$, H. Wakabayashi ${ }^{2}$ and W. F. Weeks ${ }^{1}$ \\ 1: Geophysical Institute, University of Alaska Fairbanks, \\ Fairbanks, AK $99775-0800$, U.S.A. \\ 2: Earth Observation Centre/NASDA, Saitama, JAPAN 350-03
}

\section{ABSTRACT}

Spatial and temporal backscatter intensity $\left(\sigma^{\circ}\right)$ variations from ice growing on shallow lakes during winter 1991-92 near Barrow. NW Alaska, have been quantified for the first time using ERS-1 C-band SAR data acquired at the Alaska SAR Facility. A ficld and laboratory validation program, including measurements of the thickness and structure-stratigraphy of the ice, indicates that $\sigma^{\circ}$ values are strongly dependent on whether the ice freezes to the lake bottom, or remains afloat. Backscatter intensity decreases significantly when the ice grounds on the bottom. Strong backscatter from floating ice is attributed to a spocular ice-water interface and vertically oriented tubular bubbles. During the spring thaw, backscatter undergoes a reversal; $\sigma^{\circ}$ values from ice that was grounded increase, while $\sigma^{\circ}$ values from ice that was afloat decrease. This phenomenon has not previously boen reported.

Keywards: ERS-1, backscatter, lake ice, Alaska

\section{INTRODUCTION}

The $\mathrm{X}$-band and $\mathrm{L}$-band radar signatures of ice-covered lakes in late winter on the Alaskan North Slope were first investigatod over a decade ago using airborne real aperture radar. The radar images showed interesting spatial variations in radar returns that were atuributed to the effects of bubbles and to whether the ice was floating or frozen to the lake bed (Sellmann ot al., 1975: Elachi et al.. 1976; Weeks et al.. 1977, 1978, 1981). A multi-temporal series of X-band radar images also clearly demonstrated how the radar returns changed during the course of the ice growth season as the area of ice frozen to the lake bed increased (Mellor, 1982).

The previous investigations of the radar returns from the tundra lakes relied exclusively on uncalibrated photographic products; thus, it was not possible to quantify the spatial and temporal variations in backscatter intensity, i.e., $\sigma^{\circ}$ values. In January 1992 radiometrically calibrated, digital ERS-1 SAR data were released from Alaska SAR Facility to the scientific community. SAR data acquired at ASF during winter 1991-92 included a ime-series of seenes of the Barrow region (Fig. 1) in north-west Alaska where there are hundreds of shallow tundra lakes. Spatial and temporal variations in backseatter intensity from ice growing on those lakes have been derived from ERS-1 digital SAR scenes.

This paper presents the results of the field, ice characterization and SAR data analysis program. The ice characteristics and SAR data have also bcen used to formulate and test the first numerical model of backscaucr from lake ice, which is described elsewhere in this conference proceedings (Wakabayashi et al., 1993).

\section{METHODS}

Field work was undertaken near Barrow in late April 1992. The purpose of the fieldwork was to locate the floating and grounded portions of selected lakes and to obtain ice cores for analysis of ice crystalline structure and air inclusion variations in the floating and grounded ice. The depth and state of the snowcover was noted at each sampling location. A total of 11 sampling sites were visited on seven lakes (Fig. 1). The 1992 field data are supplemented by observations made at a number of lakes in spring 1990 (Fig. 1).

For each lake that was sampled in late April the backscatter intensity $\left(\sigma^{\circ}\right)$ was determined from seventeen low-resolution $(100 \mathrm{~m}$ pixel size, $240 \mathrm{~m}$ resolution) scenes obtained during winter 1991.92, beginning in late September 1991 when the lake ice cover was first established. A timeseries of digital number (DN) profiles across Sukok Lake (Fig. 1) was also compiled to illustrate spatial changes in backscatter during the ice growth season. DN values are proportional to $\sigma^{\circ}$ values.

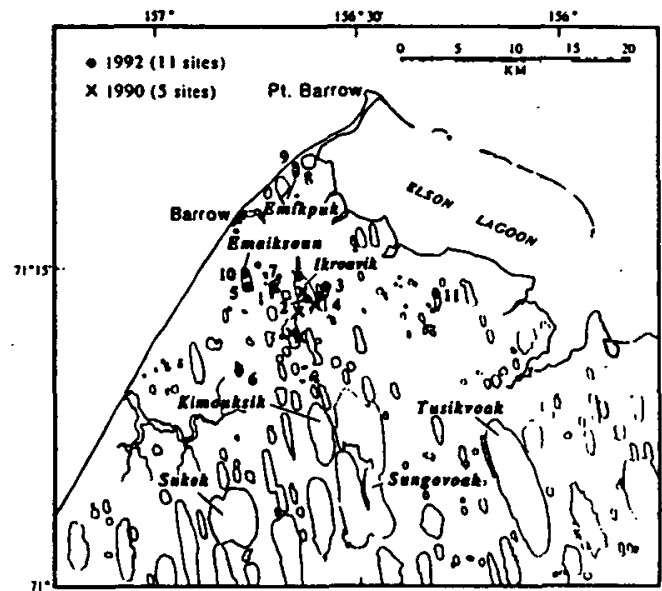

Fig. 1. Location map of sampling sites on lakes near Barrow, Alaska, in April 1992 (dots) and May 1990 (crosses).

\section{LAKE ICE STRUCTURAL-STRATIGRAPHIC CHARACTERISTICS} 3.1 Ice and snow characteristics

Variations in snow depth, ice thickness and whether the ice was floating or grounded on the lake bottom at the time of sampling are summarized in Table I. The ice was floating at six sampling sites and was frozen to the lake bottom at five others. Where water was present below the ice it occurred as only a very thin layer, sometimes only a few millimetres in thickncss. The snowcover was dry and packed hard in most cases. Occasionally, the wind had blown the snow completcly away, exposing patches of bare ice.

Table 1. Summary of snow and ice characteristics at each sampling site

$\begin{array}{ccccc}\begin{array}{c}\text { Sampling } \\ \text { site }\end{array} & \begin{array}{c}\text { Sampling } \\ \text { date }\end{array} & \begin{array}{c}\text { Snow depth } \\ (\mathrm{mm})\end{array} & \begin{array}{c}\text { Ice thickness } \\ (\mathrm{m})\end{array} & \begin{array}{c}\text { Floating or } \\ \text { groundcd }\end{array} \\ 1 & \text { 19 April } & 30 & 1.945 & \text { Floating } \\ 2 & 19 \text { April } & 60-80 & 1.59 & \text { Floating } \\ 3 & 19 \text { April } & 30 & 0.53 & \text { Grounded } \\ 4 & 19 \text { April } & 26 & 0.24 & \text { Grounded } \\ 5 & 20 \text { April } & 0-50 & 2.1 & \text { Floating } \\ 6 & 20 \text { April } & 80 & 1.18 & \text { Grounded } \\ 7 & 20 \text { April } & 20 & 0.52 & \text { Grounded } \\ 8 & 20 \text { April } & 50 & 2.005 & \text { Floating } \\ 9 & 28 \text { April } & 25 & 2.16 & \text { Floating } \\ 10 & 29 \text { April } & 60 & 2.04 & \text { Floating } \\ 11 & 29 \text { April } & 30 & 0.77 & \text { Grounded }\end{array}$

3.2 Crystalline Structure and Stratigraphy

The ice cores contained three particular types of ice:

1) granular ice containing roughly spherical bubbles, probably snow-ice;

2) inclusion-free ice, some with the columnar texture indicating congelation crystals with horizontal $c-a x e s$, and some with the massive, single crystal structure typical of congelation icc with vertically-oricnted c-axes;

3) columnar and massive single congelation ice crystals containing tubular (cylindrical) bubbles oriented roughly normal to the ice surface, i.e. parallel to the ice growth direction. 
The granular ice occurred at the top of cores from six locations (sites 2, 3, 5, 6, 7 and 11, Fig. 2). Clear ice occurred at all sites, either as the uppermose layer or directly below the bubbly, granular ice (Fig. 2). Ice with tubular bubbles occurred as the lowermost layer at all locations (Fig. 2).

The thickness of the granular layers varied between $0.03 \mathrm{~m}$ and $0.22 \mathrm{~m}$. The inclusion-free layer thicknesses ranged from $0.14 \mathrm{~m}$ to $1.18 \mathrm{~m}$. The depth below the surface at which tubular bubbles appeared varied from $0.26 \mathrm{~m}$ to $1.18 \mathrm{~m}$. Tubular bubbles appeared earliest at the shallowest lake sites where the ice was frozen to the boutom when the samples were obtained (Fig. 2). The thickness of the ice layers with tubular bubbles ranged from $0.27 \mathrm{~m}$ 10 $1.32 \mathrm{~m}$.

\subsection{Bubble characteristics}

In the surface granular layers, the mean bubble diametes ranged from $0.7 \mathrm{~mm}$ (site 2) to $4.6 \mathrm{~mm}$ (site 3), and the number of bubbles varied between $10.8 \times 10^{3} \cdot \mathrm{m}^{3}$ to $2,471 \times 10^{3} \cdot \mathrm{m}^{3}$. The density of tubular bubbles at the base of the ice varied between $0.4 \times 10^{3} \cdot \mathrm{m}^{2} 10411 \times 10^{3} \cdot \mathrm{m}^{2}$. The radius of the tubular bubbles ranged from $0.15 \mathrm{~mm}$ to $1.2 \mathrm{~mm}$. The largest diametcr bubbles were found only at site 2 (Fig. 3); otherwise, the majority of tubular bubbles had a small radius averaging $0.4 \mathrm{~mm}$. The mean length of ubular bubbles ranged from $140 \mathrm{~mm}$ at Site 11 to $91 \mathrm{~mm}$ at Site 2. The shortest and longest bubbles had lengths of $7.0 \mathrm{~mm}$ and $178.0 \mathrm{~mm}$ respectively. At any given sampling site, the densily and mean diameter of the tubular bubbles varied with depth (Fig. 3). Consequently, the ice with tubular bubbles comprised a number of sub-layers (Fig. 2).

\section{VARLATIONS IN BACKSCATTER INTENSITY}

\subsection{Temporal changes in backscatter intensity $\left(\sigma^{\circ}\right)$}

For cach lake that was sampled in late April, changes in backscatter intensity as a function of ume were determined for the central portion of the lake. The results for selected lakes are shown in Fig. 4.

In late September when ice began to grow on the lakes, $\sigma^{\circ}$ values were in the range -16 to $-22 \mathrm{~dB}$. By mid- to late October, values at all sites had increased $10-1200-15 \mathrm{~dB}$. From late October onward, $\sigma^{\circ}$ values at site 7 decreased further before levelling off in late December at $-18 \mathrm{~dB}$, where they remained throughout the winter. At site 11 , maximum $\sigma^{\circ}$ values of -12 to $-13 \mathrm{AB}$ were reached in early December, then decreased during December and remained constant at -17 to $-18 \mathrm{~dB}$ from early January to late April.

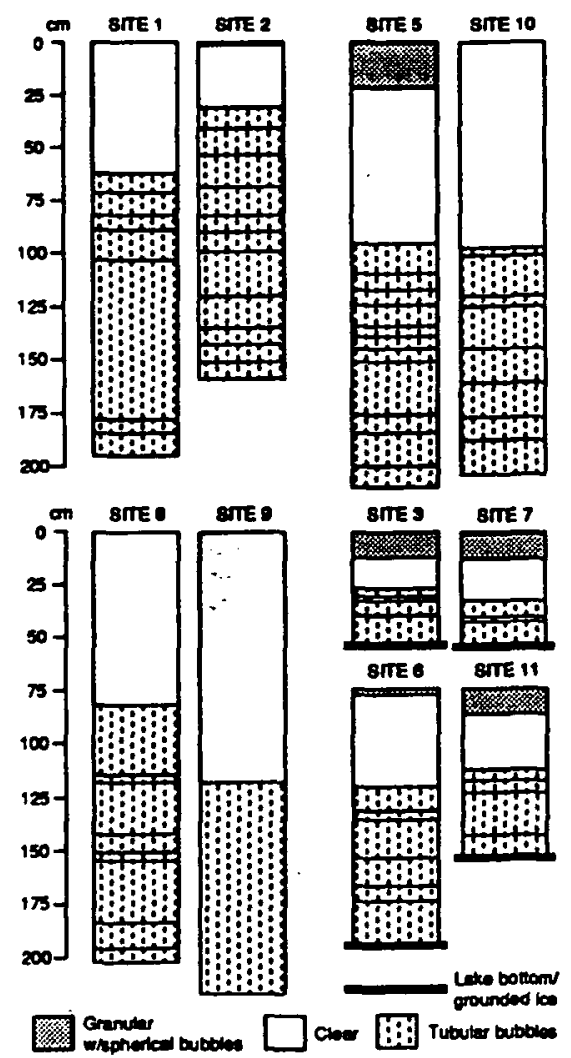

Fig. 2. Stratigraphy diagrams for ice cores illustrating the amount and disuribution of ice types present, and those locations where the ice was frozen to the lake botiom. The horizontal lines in the ubular bubble layers represent sub-layers within that ice.
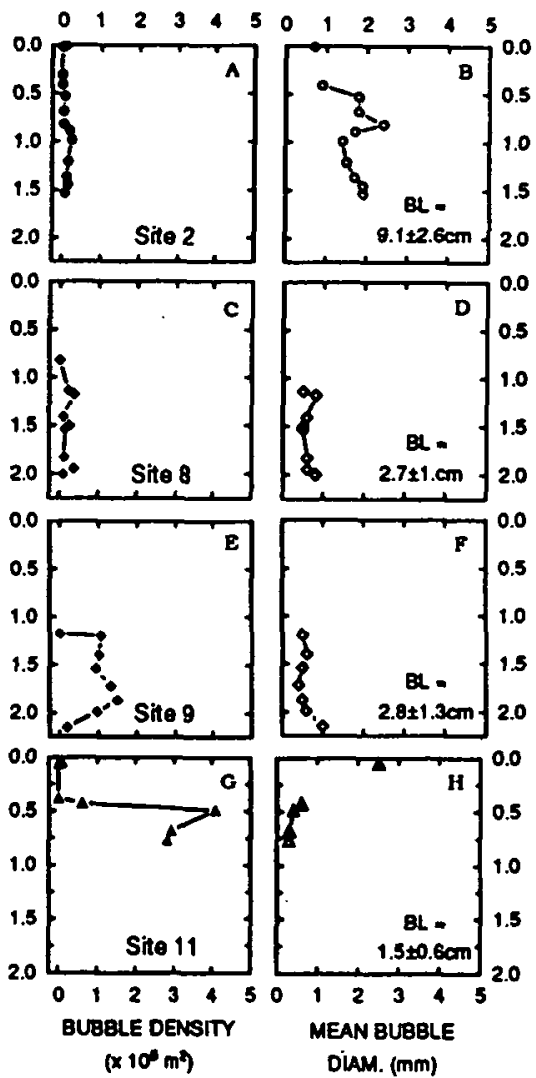

Fig. 3. Profiles of bubble density and bubble diameter at selected sites. BL is the mean length of the tubular bubbles. Sites 8 and 9 were on the same lake ( 50 Fig. 1).

Backscatter intensity at site 6 reached a maximum of $-5 \mathrm{~dB}$ in early January, but by early February had decreased $10-17 \mathrm{~dB}$ where it remained quite constant through late April. At Sites 1 and 2, $0^{\circ}$ values had increased to $-510-6 \mathrm{~dB}$ by late January and remained quite constant at those values for the rest of the winter.

From late April to carly June, backscatter intensity went through a reversal. In late May, backscatter intensity at sites 6,7 and 11 had risen to $-12 /-14 \mathrm{~dB}$, while at sites 1 and 2 it had fallen to $-12 /-14 \mathrm{~dB}$. By early June. backscatter intensity at sites 6,7 and 11 had reached $-7 /-10 \mathrm{~dB}$, while at sites 1 and 2 it had decreased further to $-17 /-19 \mathrm{~dB}$.

4.2 Spatial and temporal backscatter change at Sukok Lake

The time sequence of spatial changes in digital number (DN) values for Sukok Lake shown in Fig. 5 provides a semi-quantitative illustration of a number of the items noted in the previous section. In late September the DN values are very low (minimum 40) across most of the lake, but as the autumn progresses they rise and by 1 December have increased to 140-150 across most of the lake (Fig. Sa).

Between the beginning and the end of December there is a significant increase in DN values, from 140-150 to 180 respectively, but at the same time DN values at the lake margins drop to $100-140$ (Fig. $5 \mathrm{~b}$ ). From late December to late January there is a steady increase in DN values to as much as 200-210 across the lake, with a strong discontinuity at the margins where the DN values remain at $100-140$ (Fig. Sb).

From the end of January to late April there are significant changes in the DN values (Figs Sc and Sd). The marginal area of low DN values increases as the DN values fall to as low as 85 , while the central area of high DN values shrinks as the DN values decrease to 175 .

4.3 lce growth, structure and backscatter variations

At each site that was sampled in 1990 and 1992, ice that was frozen to the lake bed corresponded to areas of low backscatter in the SAR scenes, and ice that was floating corresponded to areas of high backscatter. These observations add to the evidence that the low backscatter is due to the low diclectric contrast of the ice-soil interface, resulting in strong attenuation of the radar signal and minimal returns to the radar antenna (Sellmann ct al., 1975; Elachi et al., 1976; Weeks et al., 1977, 1978, 1981; Mellor, 1982). 


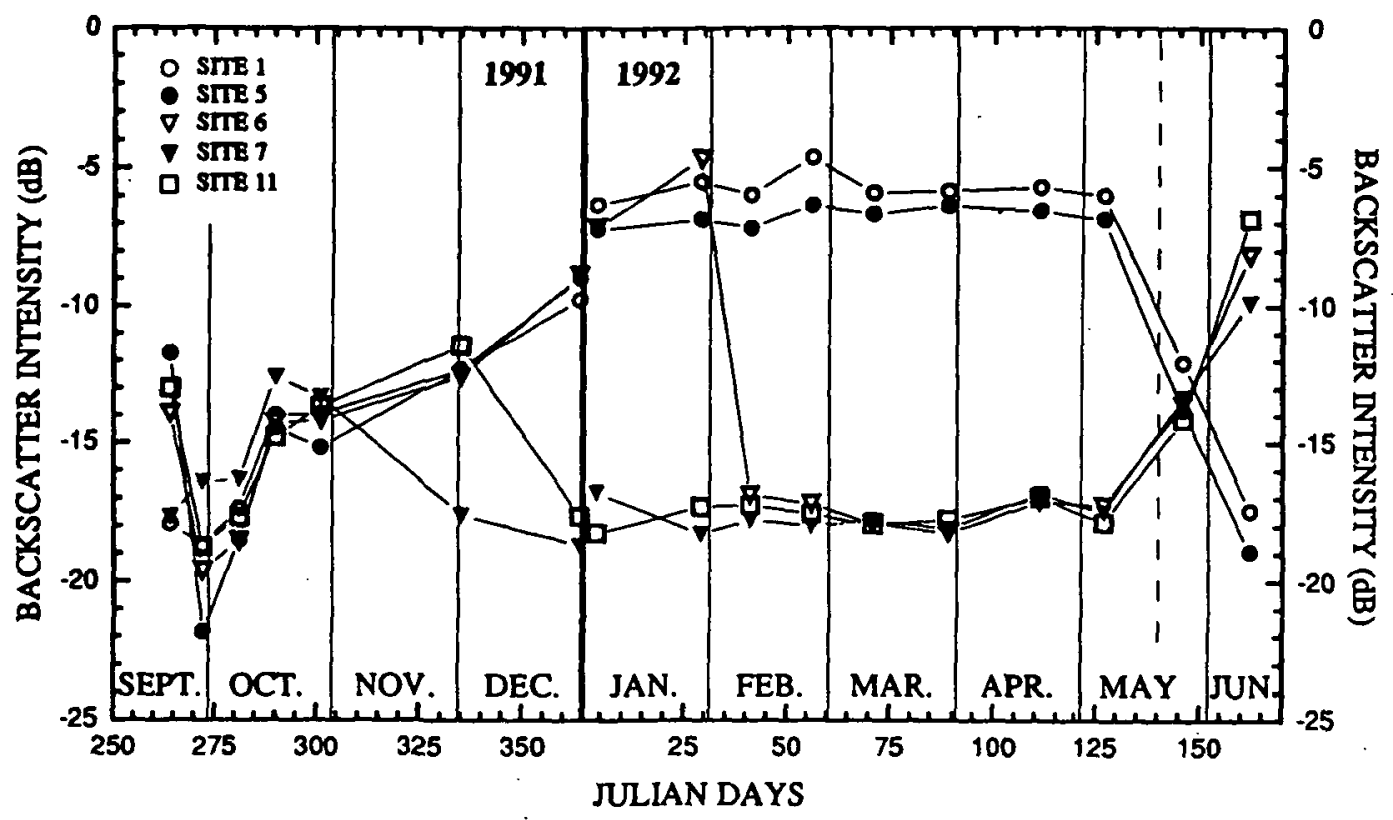

First day of mean daily temperatures above $0^{\circ} \mathrm{C}$

Fig. 4. Backscauter coefficien $\left(\sigma^{\circ}\right)$ changes as a function of time for a selection of lakes.

PLXEL NUMBER
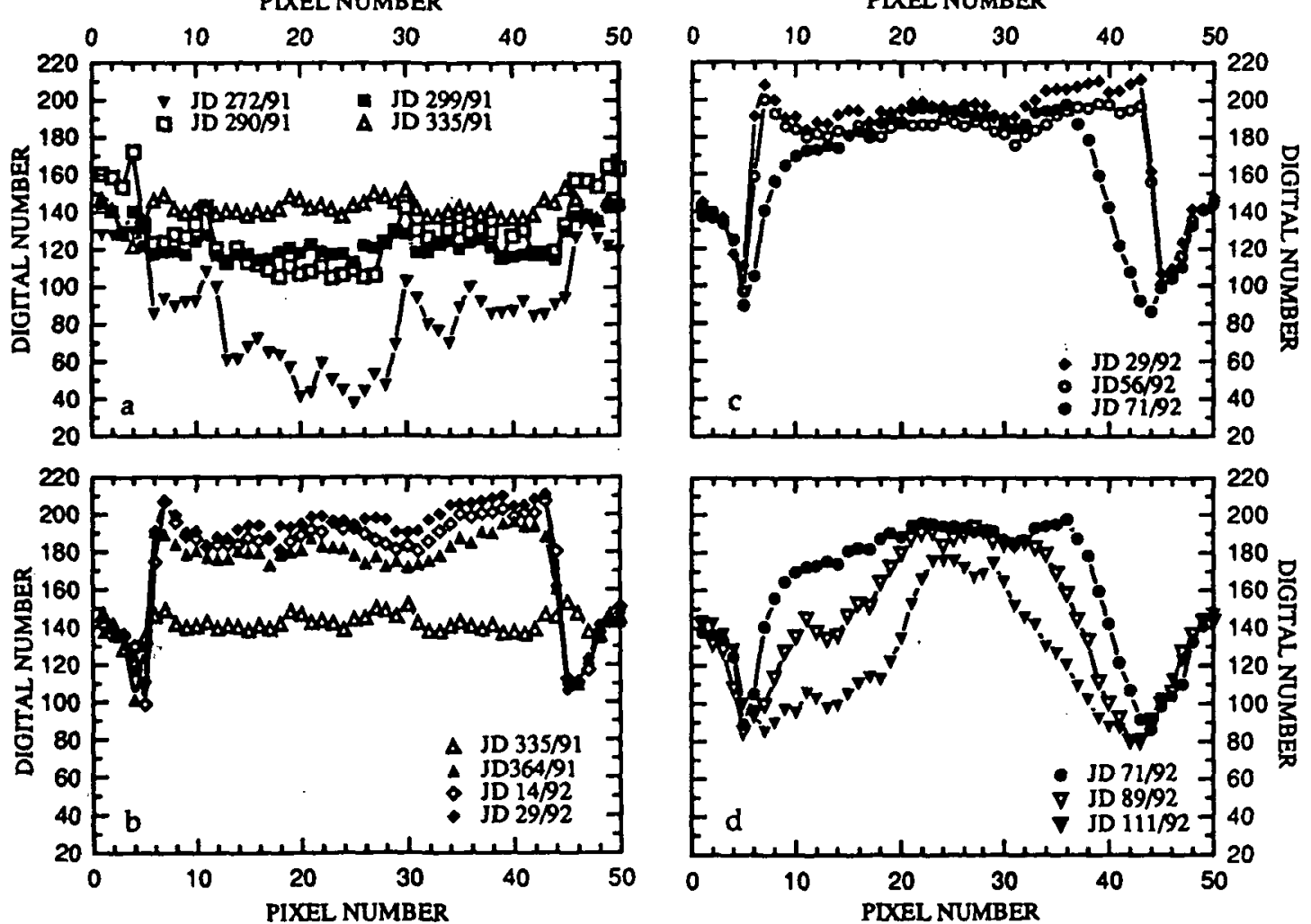

Fig. 5. Profiles of spatial changes in digital number (DN) values along the same transect across Sukok Lake from late September 1991 to 20 April 1992. The Julian dates (JD) correspond w the following calender dates: 272:29 September 1991; 290:17 October 1991; 299:26 October 1991; 335:1 December 1991: 364, 30 December 1991; 14:14 January 1992; $29: 29$ January 1992; 56:25 February 1992; $71: 11$ March 1992; 89:29 March 1992; 111:20 April 1992. 
Backseatter from the ice was also low at the beginning of the growth season (Figs 4 and 5). This can be atcributed to specular reflection away from the radar antenna of the smooth horizontal surfaces (upper and lower) of the thin ice. As the ice thickened, backscalter values rose steadily, except for those lakes that.were subsequently found to be frozen to the bottom. Backscatter from those lakes fell at different times during the winter (Fig. 4) when, it can be safely assumed, the ice first froze to the bottom. The changing backscatter profiles across Sukok Lake (Fig. S) can be interpreted as a record of the progressive frecing of the ice to the lake bottom.

At all sites where the ice was frozen to the lake bed, tubular bubbles were observed in the ice. This indicates that the tubular bubbles serve largcly as forward scatterers as the radar signal passes through to the base of the ice. Since there is a minimal retum to the radar once the ice is frozen to the hottom, the strong backscatter that is observed in the ice prior to grounding and in the ice that remains afloat all winter must require the presence of both an ice-water interface and the tubular bubbles.

An ice-water interface has a strong dielectric contrast that will give rise to specular reflection away from the radar (Weeks et al., 1978). However, at the time the lakes were sampled, there was strong backscatter at those sites where the ice was still floating. The only explanation for the strong backscatter is the presence of the tubular bubbles, which would cause volume scattering of the radar signal once it had been reflected off the icewaler interface (Weeks et al., 1978).

The significant role of the tubular bubbles is illustrated by the backscatter differences between the ice that remained afloat and that which was frozen to the lake bed at the end of April. With $\sigma^{\circ}$ values of $-510-6 \mathrm{~dB}$, backscatter from the floating ice is significantly greater than the backscatter from the grounded ice $(-15$ to $-18 \mathrm{~dB})$. A similar large difference exists between the backscatter from ice that remained afloat in April and backscatter from the same ice at the beginning of the growth season (Sites 1 and 2. Fig. 4). It is also worth noting that the backscatter from the grounded ice is similar to the backscatter from the new ice that began to grow in September (Fig. 4). This similarity in backscatter provides an indication of the effectiveness of the new ice as a specular reflector prior to tubular bubble development

Earlier studies of the SAR signatures of ice on shallow Arctic lakes have emphasized the importance of the tubular bubbles (Sellmann et al., 1975; Elachi et al., 1976: Weeks et al., 1977, 1978, 1981; Mellor, 1982). No previous mention has been made of the possible impact on backscatter variability of the bubbly snow-ice layer at the surface (Fig. 2). Some indication of the relative importance of the bubbly surface layer can be gained from a comparison of backscatter at Sites 1 and 2. Both sites were on the same lake (Fig. 1), but only Site 2 had a bubbly surface layer. Despite the physical difference between each site, there is a negligible difference in backscatter at each site. Thus, it appears that the effects of the tubular bubbles far exceed any effects due to the presence of bubbly snow-ice layers.

Unusual changes in backscatter intensity have been recorded during the spring thaw period in May and June; i.e.. backscatter from those lakes that were grounded for most of the winter increased, while backscatter from those lakes that had remained afloat all winter decreased. This backscatter reversal has not previously been observed and as yet we have no explanation for the phenomenon, other than that it probably relates to changes in the state of the ice.

\section{CONCLUSION}

A winter 1991-92 time-series of radiometrically calibrated ERS-1, C-band SAR data of the Barrow, Alasta region was acquired at the Alaska SAR Facility. Spatial and temporal backscatter intensity variations from ice growing on lakes near Barrow have been derived for the first time. The SAR data show strong backscaucr variability related to ice growth, development of tubular bubbles and freezing to the bottom. There is strong attenuation of the radar signal once a lake freezes to the botlom, regardless of the presence of tubular bubbles in the ice. The tubular bubbles are effective scatterers providing a strong return signal to the radar only as long as the ice is floating and a specular ice-water interface is present. Time-series of backscatter variations from these shallow tundra lakes arc, therefore, a record of, I) the development of wbular bubbles in the ice and, by association, gas saturation of the underlying water, and 2) the freezing of ice to the boutoms of the lakes and, therefore, lake bathymetry. The availability of a radiometricallycalibrated SAR time series has also allowed us to report for the first time an unusual backscatter reversal during the thaw period. The reversal is probably due to changes in the nature of the lake ice cover which remain to be determined.

\section{ACKNOWLEDGEMENTS}

This work was supported by NASA Polar Program Grant NAG 5-1731. Dorothy Hall and Kim Peterson assisted with fieldwork under trying conditions. Kirk Walker and Kim Morris assisted with the analysis of ice structure and stratigraphy, and SAR data.

\section{REFERENCES}

Bari, S. A.and J. Hallett, 1974. Nucleation and growth of bubbles at an icewater interface. Journal of Glaciology 13:489-520.

Elachi, C., M. L. Bryan and W. F. Weeks, 1976. Imaging radar observations of frozen Arctic lakes. Remote Sensing of Environment 5:169-175.

Gow, A. J. and D. Langston, 1977. Growth history of lake ice in relation to its stratigraphic, crystalline and mechanical structure. CRREL Rcport 77-1.

Mellor. J., 1982. Bathymetry of Alaskan Aretic lakes: a key to resource inventory with remote sensing methods. Ph.D. Thesis, Institute of Marine Sciences, University of Alaska.

Sellmann, P. V., W. F. Weeks and W. J. Campbell, 1975. Use of sidelooking airborne radar to detcrmine lake depth on the Alaskan North Slope. CRREL Special Report 230.

Wakayabashi, H., W. F. Weeks and M. O. Jeffrics. 1993. A C-band backscatter model for lake ice in Alaska. Proceedings of IGARSS '93. Tokyo, 18-21 August 1993.

Wecks, W. F., Sellmann, P. V. and W. J. Campbell, 1977. Interesting features of radar imagery of ice-covered North Slope lakes. Joumal of Glaciology 18:129-136.

Woeks, W. F., A. G. Fountain, M. L. Bryan and C. Elachi, 1978. Differences in radar retums from ice-covered North Slope lakes. Joumal of Geophysical Research 83:4069-4073.

Weeks, W. F. A. J. Gow and R. J. Schertler, 1981. Ground-truth observations of ice-covered North Slope lakes imaged by radar. CRREL Research Report 81-19. 